\title{
Salutogenesis as a Framework for Social Recovery After Disaster
}

\author{
Mélissa Généreux, Mathieu Roy, Tracey O'Sullivan, \\ and Danielle Maltais
}

\section{Introduction}

The Salutogenic Model of Health is well established in health promotion, and the links between community assets and positive health outcomes are well recognized. Making the link between positive health and salutogenic factors in a disaster context, however, requires more discussion, as the field of disaster risk reduction (DRR) is often associated with risk and vulnerability and how to protect the population. In this chapter, we discuss how salutogenesis is relevant in disasters and how it can be incorporated into post-disaster recovery strategies to promote resilience. We present a case study from a small community in Quebec, Canada, where a salutogenic approach was used to help the community of Lac-Mégantic in its recovery from a profound tragedy.

\section{What Happened on July 6, 2013, and How Was Public Health Involved Initially?}

On July 6, 2013, in the middle of the night, a train carrying crude oil derailed in the heart of Lac-Mégantic (Quebec, Canada). This municipality has a population of 6000 resi-

M. Généreux $(\square)$

CIUSSS de l'Estrie-CHUS; Faculté de médecine et des sciences de la santé, University of Sherbrooke, Sherbrooke, QC, Canada e-mail: Melissa.Genereux@USherbrooke.ca

\section{Roy}

CIUSSS de l'Estrie-CHUS; Faculté de médecine et des sciences de la santé, University of Sherbrooke, Sherbrooke, QC, Canada

Quebec National Institute of Public Health, Québec, QC, Canada e-mail: mathieu.roy7@usherbrooke.ca

\section{T. O'Sullivan}

Faculty of Health Sciences, University of Ottawa,

Ottawa, ON, Canada

e-mail: tosulliv@uottawa.ca

D. Maltais

Département des sciences humaines et sociales, Université du Québec à Chicoutimi, Québec, QC, Canada

e-mail: danielle_maltais@uqac.ca dents and is the seat of the Granit area, one of seven areas in the Estrie region of Quebec, Canada. This charming small town is situated on the shores of Lac-Mégantic, from which the community derives its name.

The train, with no engineer at the controls, spontaneously rolled downhill from its night stop location near Nantes toward the town of Lac-Mégantic approximately $11 \mathrm{~km}$ away. With a relatively constant downhill slope between its initial location and Lac-Mégantic, the train's descent accelerated to almost $100 \mathrm{kph}$ by the time the locomotives encountered a sharp curve in downtown Lac-Mégantic and most of the trailing cars derailed. As they derailed, 63 tank cars ruptured and escaping crude oil ignited, leading to a succession of powerful explosions and a major conflagration. The fire spread rapidly to nearby structures, destroying 44 buildings. The derailment, the explosions, and the subsequent fire also resulted in 47 deaths and necessitated the mass evacuation of 2000 persons, equivalent to one-third of the town's population.

This tragic, sudden, and unprecedented event has therefore generated significant impacts on the social, environmental, and economic levels. Indeed, coupled with the human suffering and the environmental degradation, the LacMégantic derailment caused serious psychosocial and economic consequences, including the relocation of many families forced to leave their homes, the loss of many jobs, and the closure of many local businesses for weeks before relocating elsewhere in town (Généreux et al., 2015).

Given the impact of this technological disaster on this local community, the involvement of public health personnel and resources was critical throughout the emergency response operations. The Public Health Department (PHD) for the Estrie region responded immediately, within the first hours, to provide direct services that were needed to protect the citizens of Lac-Mégantic and the on-site responders from several health hazards. The priority at that time was to assess, communicate, and manage immediate risks to public health associated with exposure to chemical, physical, and biological agents (Généreux et al., 2015). 
In the face of disasters, and despite the short-term health issues that can be of great concern in such settings, it is important to recognize that the operational domain of the public health in affected communities extends beyond health protection and disease prevention, to include the promotion of health and well-being. It is with this in mind that Estrie PHD, in collaboration with researchers in the field of psychosocial recovery, conducted a population health survey entitled "Enquête de santé populationnelle estrienne" (ESPE) in 2014. Unknowingly, this was the first of a long series of promising initiatives to mobilize the local community in this post-disaster landscape.

\section{Quantitative Methods in Addressing Challenging Environments: Monitoring the Psychosocial Impacts of Disasters}

Disasters (either technological or natural), as well as other types of collective trauma, often lead to adverse impacts for community health and well-being over the short and long term; as well as on the personal, conjugal, family, social, and professional lives of those involved. Tragic events like the Lac-Mégantic train derailment affect people and communities by causing extensive stress, as well as human and material losses. Fortunately, not everyone exposed to such events faces long-term psychosocial issues, a wide range of pre- and post-disaster-related factors being positively or negatively associated with the risk of developing such problems (Généreux et al., 2019a). It is now well understood that the recovery period can take many months, if not years, following such an event. Numerous studies indicate that physical and psychological health problems following disasters are substantial in affected communities and can persist over time in the absence of adequate support (Goldman \& Galea, 2014; Galea, 2007; Maltais et al., 2005). On the other hand, according to a number of studies, exposure to a disaster can have a positive long-term effect on the beliefs and values of certain individuals and create a stronger sense of family and collective solidarity. Some individuals may even discover personal strengths which were left untapped until then (Généreux \& Maltais, 2017; Maltais et al., 2020).

Public health organizations have to intervene and help citizens and communities to cope in the aftermath of disasters. Monitoring the physical and psychological consequences of a community struck by a disaster can help to raise awareness, tailor interventions aimed at supporting citizens, communities, and inter-sectoral partners (e.g., municipalities, schools, community organizations), and promoting resilience and recovery processes. This can serve as a powerful lever for the development and the implementation of health promotion measures that can properly respond to the evolving needs of the individual and wider community while considering local assets and capacities. It is in that spirit that Estrie PHD, in close collaboration with the "Universite $d u$ Québec à Chicoutimi" (UQAC) and the "University of Sherbrooke," has spent the first 6 years tracking the evolving health of those living in the Granit area using repeated crosssectional population-based surveys.

One year following the tragedy, in summer 2014, the PHD conducted a first health survey using a populationbased sample of about 800 respondents from the Granit area and additional 8000 respondents elsewhere in the Estrie region. Recruited at random, this representative sample of the Estrie population responded to a telephone or web survey covering a variety of physical and mental health outcomes. The second phase of the ESPE was carried out in the fall of 2015 and sought to better understand the local population's health and well-being, along with its possible link to the July 2013 railway disaster. In total, 1600 adults were recruited randomly in 2015 to take part in this large-scale telephone survey. These included 800 from the Granit area and 800 from elsewhere in the Estrie region. In the fall of 2018, a third survey, similar in nature, was conducted. Each of these three studies is composed of a separate sample of adults residing in the Granit area or elsewhere in Estrie. In other words, the participants were not monitored in time. A fourth study, funded by a federal research funding agency, was conducted in 2016 by UQAC. This additional study used a different sampling strategy, with a final sample composed of 400 adults in Lac-Mégantic, 400 adults elsewhere in the Granit area, and no "control group" from elsewhere in the Estrie region. For this reason, results from the 2016 survey are hardly comparable with those from the three other surveys (Maltais et al., 2019a, b).

Adults who agreed to participate in any of these studies were asked to answer an anonymous questionnaire, which lasted an average of approximately $30 \mathrm{~min}$. A number of questions were identical across all three surveys, allowing for the comparability of results over time (years 1 to 5 following the tragedy). Various psychosocial outcomes were examined over time, including not only adverse effects of disasters (e.g., psychological distress, depressive episodes, signs of post-traumatic stress, diagnosed anxiety or mood disorders, social worker or psychologist consultation, anxiolytic drug use, alcohol abuse) but also positive ones (e.g., resilience, positive mental health, sense of coherence, sense of community belonging, social support) (Généreux \& Maltais, 2017; Généreux et al., 2019b).

In each survey, three types of losses were examined: human losses (i.e., loss of a loved one, fear for one's life or that of a loved one, suffering injuries), material losses (i.e., home damage, permanent or temporary relocation, job loss), and subjective losses (i.e., perception that the event was stressful, that something important was lost, that something important was interrupted, or that harm will potentially occur 
in future). Respondents were then classified according to the following categories, and each outcome was compared to these specific levels of exposure (Généreux \& Maltais, 2017, Généreux et al., 2019b):

- High exposure: All three types of losses (human, material, and subjective) reported

- Moderate exposure: One or two types of losses reported

- Low exposure: No loss reported

Findings from the first two surveys, conducted in 2014 and 2015, were quite disturbing. In the Granit area, human losses were the most common type of loss following the tragedy with almost two-thirds of citizens experiencing such type of loss. Furthermore, about one in six adults in this area (i.e., $16.7 \%$ in 2014) reported being intensely exposed to the disaster (Fig. 49.1).

In 2014 and 2015, steep gradients were observed in the prevalence of adverse psychosocial outcomes in the Granit area as a function of the intensity of exposure to the train derailment. In 2014, adults reporting intense exposure were four times more likely to report excessive drinking as compared to those with low exposure $(15.2 \%$ vs. $3.5 \%, p=0.001)$. Similar gradients were observed for various psychosocial outcomes, both 1 year and 2 years after the train derailment (i.e., psychological distress, depressive episode, anxiety disorder, and anxiolytic drug use). Some adverse psychosocial outcomes were examined in 2015 only. Findings from the 2015 wave notably revealed that three quarters $(76.1 \%)$ of adults in the Granit area intensely exposed showed moderate to severe signs of post-traumatic stress 2 years after the disaster. Interestingly, in 2015, environmental problems were still perceived as more frequent among intensely exposed adults in the Granit area as opposed to less exposed ones (Fig. 49.2).

Finally, some significant time trends from year 1 to year 2 post-disaster were also observed. While most psychosocial out-

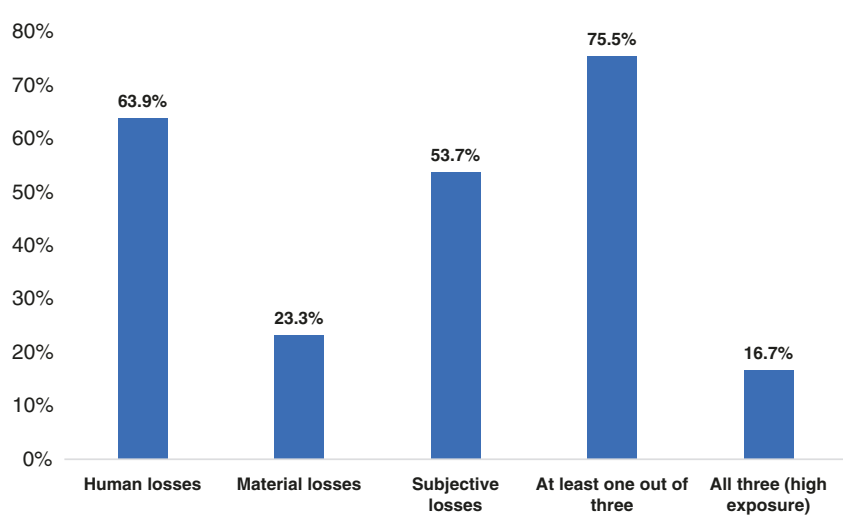

Fig. 49.1 Type and intensity of exposure to the 2013 Lac-Mégantic train derailment, ESPE 2014 (Granit area, 811 adults) comes did not show any statistically significant improvement among these adults (Fig. 49.3), the use of psychosocial services decreased by half among intensely exposed adults between 2014 (26.9\%) and 2015 (15.9\%) (Généreux et al., 2019b).

In addition to adverse psychosocial outcomes, a diverse set of asset-based outcomes should be considered in postdisaster contexts. Several health asset indicators were assessed both in ESPE 2014 and 2015 (i.e., resilience, positive mental health, sense of community belonging). In 2014 and 2015, regardless of the intensity of exposure to the tragedy, about half of respondents had a high level of resilience score based on the Connor and Davidson resilience scale (score $\geq 30$; Connor \& Davidson, 2003). Regarding positive mental health, based on Keyes' scale (Keyes, 2002, 2005), it was observed that intensely exposed adults were less likely to report optimal mental health in 2015 (as opposed to low exposed ones), while no such differences were observed in 2014. These findings suggest that the stock of health assets can weaken with time among people directly impacted by a

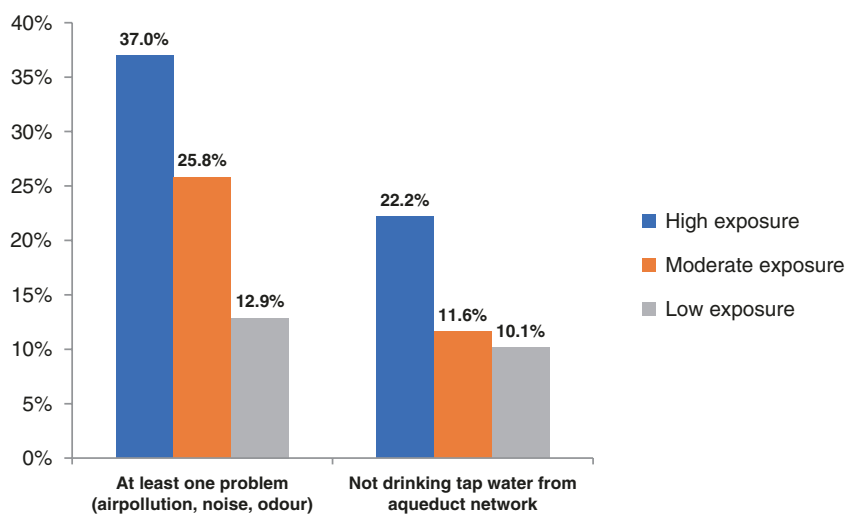

Fig. 49.2 Perception of various environmental problems as a function of the intensity of exposure to the Lac-Mégantic 2013 train derailment, ESPE 2015 (Granit area, 800 adults)

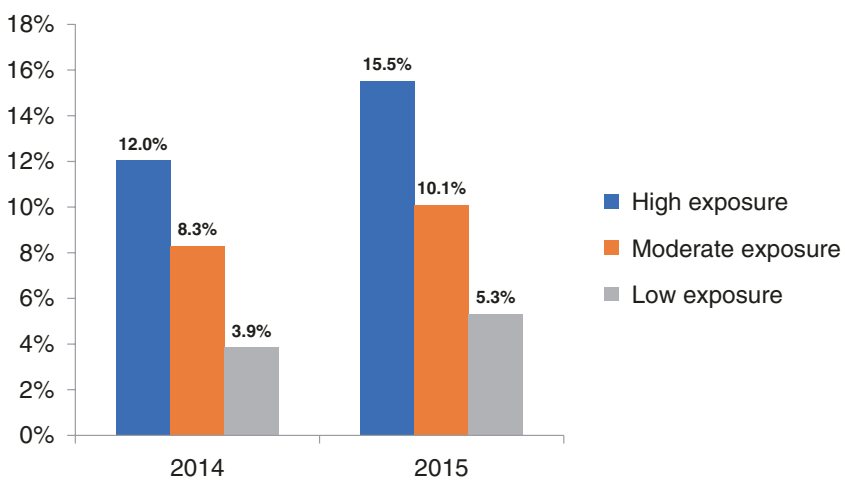

Fig. 49.3 Diagnosed anxiety disorders as a function of the intensity of exposure to the Lac-Mégantic 2013 train derailment, ESPE 2014 and 2015 (Granit area, 811 and 800 adults, respectively) 
disaster, especially in the absence of adequate support and services.

The short version ( 3 items) of the sense of coherence was also measured (Lundberg \& Nyström Peck, 1995), but only in 2015. A low sense of coherence was observed among $24.5 \%$ of adults residing in Lac-Mégantic, regardless of the level of exposure, and this proportion was significantly lower than that observed elsewhere in the Estrie region (13.6\%). Interestingly, a low SOC-3 score was found to be one of the strongest predictors of severe signs of post-traumatic stress, even stronger than having suffered human or material losses. Overall, the use of asset-based outcomes was judged as useful, not only to take into account the strengths and capacities of the community but also to point out strategies specifically targeting these protective factors.

\section{Qualitative Methods in Addressing Challenging Environments: Asset Mapping and Co-construction of an Action Plan After Disasters}

Over the past decades, many positive health concepts emerged in science (e.g., self-efficacy, resilience, social support or participation, civic engagement). From Antonovsky's original theory, a salutogenic orientation emerged. This orientation goes beyond the sense of coherence or any other positive health concepts with a perspective that unites measures on capacities. Extensive research has shown that having a higher stock of assets has a positive influence on health. This assertion is true directly and indirectly as studies have identified direct associations between assets and better health; as well as indirect associations in which assets moderated the effects between unhealthy states or behaviors and undesirable outcomes (Levasseur et al., 2017; Roy et al., 2018).

There is currently a paucity of knowledge on communitylevel strategies that enhance health, well-being, and resil- ience in a post-disaster landscape in an effective manner. While much is known about strategies targeting vulnerabilities following disasters and emergencies, less is known about what could activate resilience. This tendency to focus on what is going wrong after a collective trauma requires significant resources and could promote dependency on limited services (Kretzmann \& Mcknight, 1993; Ziglio et al., 2000). This leads to interventions working on needs and problems (i.e., deficit-based approach) rather than fostering capacities and resources (i.e., asset-based approach) (Morgan \& Ziglio, 2007; Lindstrom \& Eriksson 2010). An asset-based approach was proposed, to shift the focus toward what could produce health and well-being instead of diseases and psychosocial problems in Lac-Mégantic. This approach draws inspiration from the salutogenic theory (Antonovsky, 1987, 1996).

The release of the ESPE 2015 data (i.e., in February 2016) stimulated the emergence of health promotion and advocacy interventions for the local population. Given the magnitude of the tragedy, it was necessary to take a step back to understand and situate ourselves in relation to the normal process of community recovery. It was in this context that in March 2016, the Estrie PHD intensified its work with community partners, first by organizing a day of collective reflection. The purpose of holding a collective reflection day was to work together to gain control of the situation and reverse the cycle. During this day, no fewer than 50 key actors (decisionmakers, stakeholders, citizens, and experts) gathered. The reflection day was divided into two parts: (1) conference and workshops on resilience and lessons learned from the past, and (2) conference and workshops on levers for long-term recovery and priorities for the future. A defining moment was the asset mapping activity through which participants were invited to construct together a historical timeline that traces key milestones in the recovery of their community and to recognize the progress made (Fig. 49.4). By highlighting a series of interventions and initiatives previously implemented by social workers and other partners, the group was

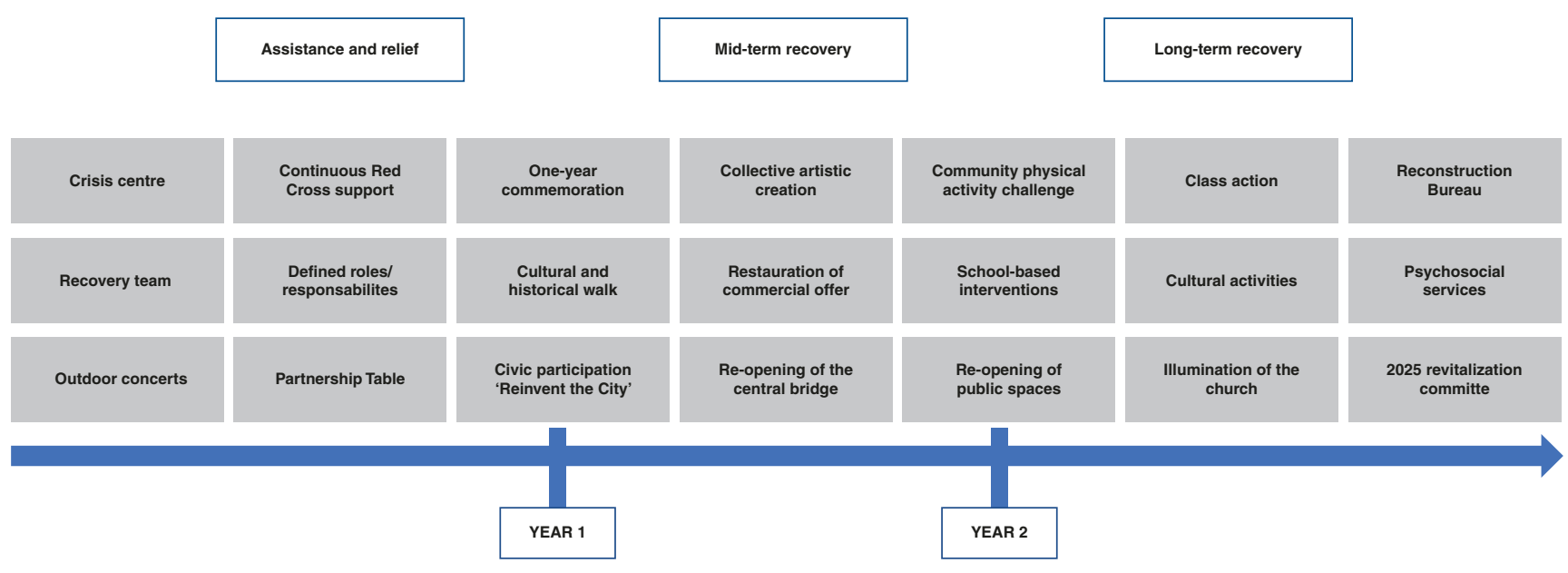

Fig. 49.4 Historical timeline tracing key milestones in the recovery of Lac-Mégantic community (March 2016) 
able to identify benefits at the individual and community level, as well as features common to the actions that created positive effects.

Throughout the "collective reflection day," a common vision of the desired future emerged and priorities for action and research were identified, leading to the co-construction of what would become the "Plan for the Recovery and Development of a Healthy Community in Lac-Mégantic and the Granit area." This plan pursues the following objectives:

- Maintain and adapt psychosocial services to the needs of individuals and the community (outreach services).

- Stay connected with the community.

- Promote community involvement.

In the weeks following the elaboration of the plan (i.e., April 2016), Estrie PHD advocated for additional funding to support its implementation. In June 2016, the "Ministère de la Santé et des Services sociaux" (MSSS) and the Canadian Red Cross announced substantial investments that would serve as financial levers to implement the adopted action plan. The ESPE data were an important contribution supporting an informed decision, based on a fair understanding of the long-term psychosocial impacts of the 2013 tragedy.

In sum, holding such a day of reflection, which brought together key players from the community, contributed to the development of a common vision of solutions and the transmission of a clear, coherent, and positive message to decision-makers and the community.

"Building a project together is really motivating. Especially since everyone feels involved: from citizens to elected officials. It was a very inspiring day!'

- A participant of the collective reflection day

This positive experience supports the fact that beyond traditional surveys, qualitative methods are valuable for listening to, learning from, giving voices to, and engaging local partners and high-risk citizens. Through inclusive and empowering approaches, public health practitioners and researchers can better integrate members of the community as assets rather than victims and take into considerations their capacities in addition to their needs (O'Sullivan et al., 2014).

\section{A Community Outreach Team, Based on a Multilevel Approach}

One of the components of the action plan was the creation of a permanent community outreach team in Lac-Mégantic in the summer of 2016. Located outside formal clinical settings (i.e., in the downtown area), this unique multidisciplinary team aims to bring psychosocial services closer to the population. It is composed of four full-time professionals (two social workers, one outreach worker, and two community organizers) and two part-time professionals (a kinesiologist and a nutritionist).

The following principles guided the entire Lac-Mégantic outreach approach: global health, prevention, scientific rigor, a strengths-based approach, empowerment, interorganizational and intersectoral collaboration, and inclusion. Citizen participation and community development were at the heart of this approach. A wide range of services are offered, ranging from daily interactions with citizens and local organizations (in the form of psychosocial support, response to service requests, rapid detection and response to emerging needs, collaboration with the organization of activities, etc.) to involvement in various projects emerging from the action plan (Généreux \& Maltais, 2019).

\section{Promising Initiatives to Mobilize the Local Community in a Post-disaster Landscape}

The EnRiCH community resilience framework for high-risk populations (O'Sullivan et al., 2014) inspired the strategies developed within this community to promote community resilience, health, and well-being (Généreux et al., 2018a, b). Based on qualitative research conducted in five Canadian communities and a review of scientific literature, this framework advocates for an integrated upstream and downstream approach to disaster risk. With the development and use of adaptive capacities as a central element, it advocates three pillars and four areas of intervention, as described in Fig. 49.5, all in a cultural context and working with the complexity specific to disasters.

In line with this reference framework, several promising initiatives have been implemented in recent years within the Lac-Mégantic community to activate community resilience, social cohesion, and citizen participation in a post-disaster setting. Committed to keeping track of local innovations and sharing them in formats that are suitable for both experts and practitioners, a synthesis of some of these promising initiatives has been produced and updated on an annual basis by the Outreach Team since 2017 (Généreux et al., 2018). These initiatives (e.g., social animation, Photovoice, Greeters, walking club) all contributed significantly to empowering citizens and mobilizing the community of Lac-Mégantic and surrounding areas. These initiatives also appear to have had a positive impact on the mental health and well-being of the citizens of this community.

As is generally known, organizing community projects or collective events, increasing opportunities to become involved as citizens, as well as other elements that strengthen social capital contribute to building resilience in a post- 
Fig. 49.5 EnRiCH

framework components. (Source: O'Sullivan et al., 2014)

\begin{tabular}{|c|c|}
\hline COMPONENTS & DESCRIPTION \\
\hline Adaptation capacity & Flexibility in changing environments \\
\hline \multicolumn{2}{|l|}{ Mainstay } \\
\hline Empowerment & Power to activate forces \\
\hline Collaboration & Relationship with a common vision \\
\hline Innovation & Emerging new practices \\
\hline \multicolumn{2}{|l|}{ Fields of intervention } \\
\hline Awareness and information & Collective sharing and learning \\
\hline Strength-based management & Mapping and linking forces \\
\hline Upstream leadership & Proactive resource investing \\
\hline Social connectivity & People and group networking \\
\hline Complexity & Dynamic, non-linear context \\
\hline Culture & Local community context \\
\hline
\end{tabular}

disaster context. The data collected in this regard from 800 adults in MRC du Granit in the framework of ESPE 2018 speak for themselves (Fig. 49.6) (Généreux \& Maltais, 2019).

\section{Concrete Examples of Promising Initiatives}

\section{Photovoice}

In 2017, in collaboration with the University of Ottawa EnRiCH research team and PHD of Estrie, the citizens of Lac-Mégantic took part in a Photovoice Initiative to map the assets of their community and develop a positive campaign and vision for the community looking forward to 2025. Over a 6-month period, the Lac-Megantic Photovoice Group met monthly to take photos of community assets and ideas to support their vision for the community. They met to discuss their photos with the group, and share their ideas around issues that matter to them. The Lac-Mégantic Photovoice
Group planned and hosted two exhibitions to facilitate knowledge mobilization and foster dialogue with decisionmakers in Lac-Mégantic and Ottawa, including local and federal politicians. The Photovoice Initiative was highlighted as an inspirational example of community engagement in resilience initiatives in a report by the World Health Organization (The Lac-Mégantic Photovoice Group et al., 2018).

"We could express our sadness, our emotions openly because we were welcomed, without criticism. At first, it was quite emotional, but over the meetings, this overflow was transformed into something lighter. It did me good. It made a big difference."

- A participant of the Photovoice Initiative 
Fig. 49.6 Elements that have significantly improved personal well-being over the past 12 months, ESPE 2018 (Granit area, 800 adults)

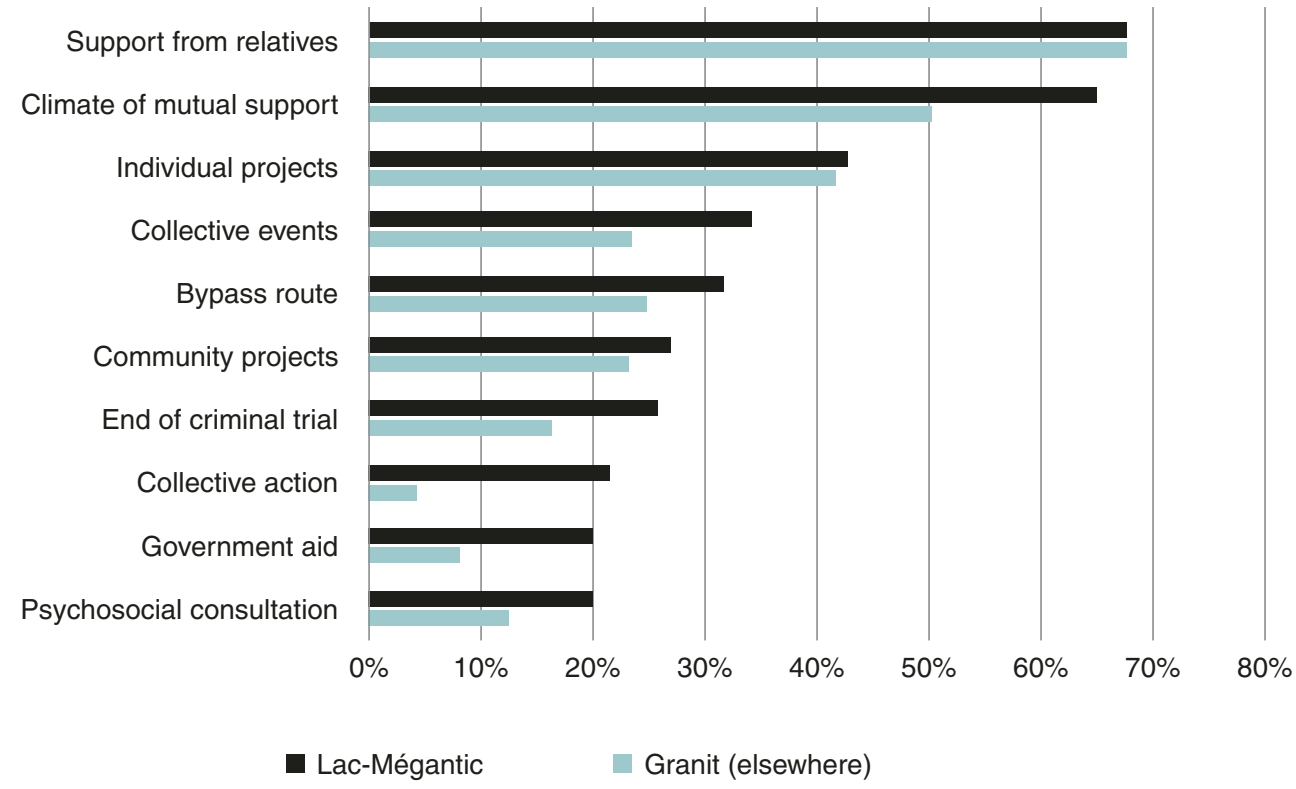

\section{Ephemeral Place}

The population is struggling to reclaim the downtown area of Lac-Mégantic, which was largely destroyed during the railway tragedy of 2013. Being under reconstruction, this new place, full of meaning and memories, constantly recalls the loss of landmarks, but also the loss of gathering places. At the same time, there is a desire among citizens to get involved and to revitalize their living environment. In 2018, the concept of Ephemeral place in the heart of the city arose from this desire, a space promoting social activities, networking, and gatherings. This outdoor venue, under the responsibility of the Outreach Team, allows the involvement of citizens of all ages and all horizons, as well as their participation in various activities aimed at bringing people together and developing meaningful links. Since these are temporary installations, it is an opportunity to experiment with concepts or ideas, while creating positive experiences. Through its free and varied leisure activities offered to citizens ( 5 to 7 with musicians, barbecues, outdoor film screening with popcorn, laughter yoga, intergenerational karaoke, etc.) and its unique approach, Ephemeral place undeniably supports the longterm recovery of the Lac-Mégantic community (Généreux et al., 2018).

\section{Lessons Learned from a Citizen's Perspective}

Inspired from a similar initiative following the bushfires which swept across Victoria, Australia, in 2009 (McAllan et al., 2011), the idea behind this project was to collect the statement of people who experienced the tragedy through one-on-one and/or group interviews and to identify overrid- ing themes. This initiative provided a voice and brought together people who wished to contribute in this way, naming what could be changed or improved as a way of managing future disasters. Through their experience, citizens could thus make recommendations to the different bodies with which they interacted during the rail tragedy of July 2013 but also during the months and years that followed it. A semistructured interview guide was developed based on the CHAMPSS Functional Capabilities Framework (O'Sullivan et al. 2013). The acronym stands for the following categories of functional capabilities: Communication, Awareness, Mobility/Transportation, Psychosocial, Self-Care \& Daily Tasks, and Safety \& Security. A dozen interviews were conducted with citizens that would not have been reached otherwise, in order to make their voice heard. Data collected through these interviews were then pooled and analyzed to draw emerging themes that were sent to participants for further validation. By being inclusive and by recognizing the various experience lived, this project gave citizens a different opportunity to contribute following the tragedy.

\section{Long-Term Trends in Psychosocial Outcomes Following a Disaster}

As in many other disaster settings, huge efforts have been made in Lac-Mégantic over the past few years to foster resilience and well-being, but has there been any progress in terms of psychosocial outcomes? With regards to all the data collected from our surveys, major findings emerge. First, the psychosocial impacts observed in the years following the Lac-Mégantic rail tragedy in 2013 seem to be receding. For 
Fig. 49.7 Diagnosed anxiety disorders following the 2013 train derailment, ESPE 2014, 2015, and 2018 (Estrie region; 8737,1600 , and 8830 adults, respectively)

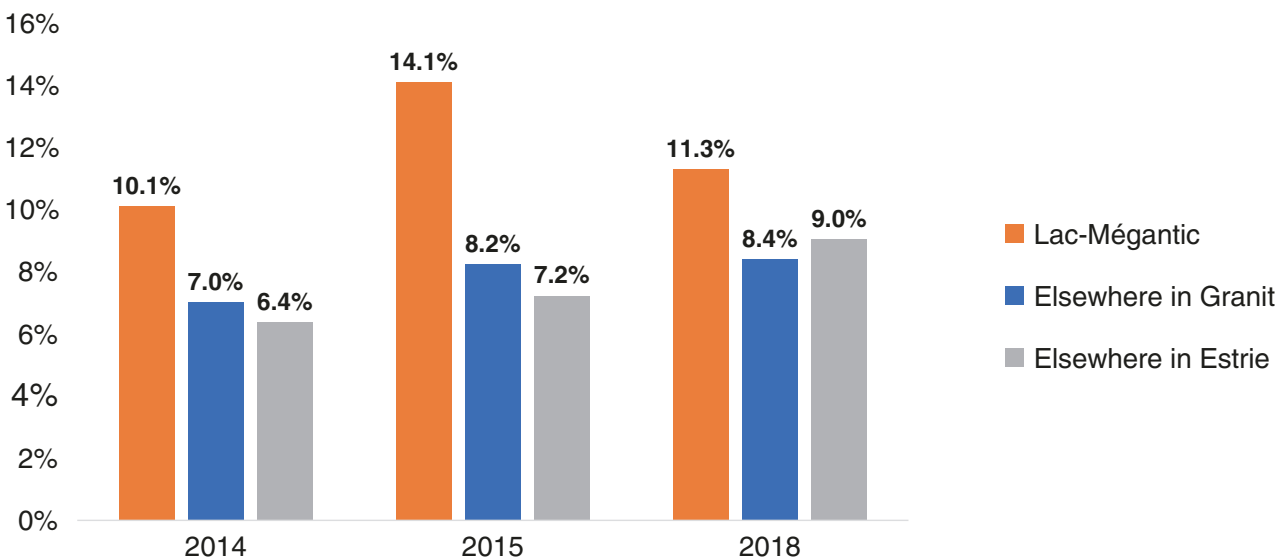

example, after reaching a peak in 2015, the proportions of adults reporting an anxiety disorder diagnosed by a doctor stabilized in 2018 in Lac-Mégantic. On the other hand, these proportions increased significantly elsewhere in Estrie from 2014 to 2018 (Fig. 49.7). In other words, the gap that had developed between Lac-Mégantic and the rest of Estrie in the first 2 years after the tragedy is no longer, in many respects.

Second, there is still a high prevalence of signs of posttraumatic stress. Despite a gradual adaptation of citizens to the losses and stressors experienced during and after the 2013 tragedy, the local community seems to have been deeply affected by the traumatic event and its aftermath. These marks could persist for many years, without preventing the proper functioning of individuals and their community. Finally, protective factors are also increasingly observed in Lac-Mégantic, particularly high social support and a strong sense of belonging to the community (Généreux \& Maltais, 2019). These factors may act as powerful moderators of the adverse effects of primary and secondary stressors typically arising from large-scale disasters.

\section{Conclusion}

Our various population studies, combined with our continuous on-the-ground presence, indicate that the psychosocial impacts resulting from the 2013 Lac-Mégantic rail tragedy decreased over time. Although this tragedy has left its mark, the local community is gradually adapting to its new reality. The asset-based approach that has been promoted seems to have contributed to this "new reality" and emphasizes the importance of social capital to activate individual and community resilience in post-disaster contexts.

This rich experience in Granit over the last 6 years enabled us to identify three key ingredients for success in supporting the recovery of citizens and social reconstruction of their community following a disaster:
1. Acknowledging the strengths of the community and promoting citizen participation

2. A strong political commitment to support the community through preventive actions, upstream of problems

3. A public health team able to support the development and implementation of these actions

To conclude, let us recall the importance of understanding, preventing, and reducing psychosocial risks in the months and years following a disaster, whether natural, technological, or intentional. In any case, concerted action to promote community resilience is required during, after, and ideally before the occurrence of such an event. As advocated by the United Nations, we must move from a disaster management logic to a risk management logic associated with these events, in partnership rather than silos for the good of the community (United Nations, 2015). The positive development of the psychosocial situation in Lac-Mégantic demonstrates the importance of developing a common understanding of risks and working together in finding solutions.

Climate change, urbanization, and the aging of the population are here to remind us that the frequency and intensity of disasters, as well as the exposure and vulnerability of the Quebec population to this type of event, are expected to increase in the years to come. Therefore, it is best to prepare for it now.

\section{Key Messages}

1. Monitoring long-term physical and psychosocial consequences through health surveys is relevant, if not essential.

2. The voices of diverse groups, including the highestrisk groups, must be heard in order to promote concrete social measures and psychosocial support tailored to their needs. 
3. The search for a balance between a deficit-based approach and an asset-based approach must be prioritized.

4. Professionals, researchers, and public health decision-makers need to work closely with local organizations and citizen groups.

5. Lessons from past experiences should inspire the actors involved in the recovery of individuals and their communities, to implement effective strategies and interventions that are effective, while avoiding reinventing the wheel.

\section{References}

Antonovsky, A. (1987). Unraveling the mystery of health. How people manage stress and stay well. Jossey-Bass.

Antonovsky, A. (1996). The salutogenic model as a theory to guide health promotion. Health Promotion International, 11, 11-18.

Connor, K. M., \& Davidson, J. R. T. (2003). Development of a new resilience scale: The Connor-Davidson Resilience Scale (CD-RISC). Journal of Depression \& Anxiety, 18, 71-82.

Galea, S. (2007). The long-term health consequences of disasters and mass traumas. Canadian Medical Association Journal, 176 $1293-1294$.

Généreux, M., \& Maltais, D. (2017). Three years after the tragedy: How the Le Granit community is coping. Bulletin Vision Santé publique. Centre intégré universitaire de santé et de services sociaux de l'Estrie - Centre hospitalier universitaire de Sherbrooke.

Généreux, M., \& Maltais D. (2019). Social reconstruction of the LacMégantic community following the tragedy: Assessment of the first six years. Bulletin Vision Santé publique. Centre intégré universitaire de santé et de services sociaux de l'Estrie - Centre hospitalier universitaire de Sherbrooke.

Généreux, M., \& The Outreach Team. (2018). Promising initiatives to mobilize the local community in a post-disaster landscape. Centre intégré universitaire de santé et de services sociaux de l'Estrie Centre hospitalier universitaire de Sherbrooke, $48 \mathrm{p}$.

Généreux, M., Petit, G., Maltais, D., Roy, M., Simard, R., Boivin, S., et al. (2015). The public health response during and after the LacMégantic train derailment tragedy: A case study. Disaster Health, 3-4, 1-8.

Généreux, M., Petit, G., Roy, M., Maltais, D., \& O’Sullivan, T. (2018a). The "Lac-Mégantic tragedy" seen through the lens of the EnRiCH community resilience framework for high-risk populations. Canadian Journal of Public Health, 109, 261-267.

Généreux, M., Petit, G., Lac-Mégantic Community Outreach Team, \& O'Sullivan, T. (2018b). Part 5: Public health approach to supporting resilience in Lac-Mégantic: The EnRiCH framework. In E. Ziglio (Ed.), Health 2020 priority area four: Creating supportive environments and resilient communities. A compendium of inspirational examples (pp. 156-162). World Health Organization.

Généreux, M., Schluter, P. J., Takahashi, S., Usami, S., Mashino, S., Kayano, R., \& Kim, Y. (2019a). Psychosocial management before, during, and after emergencies and disasters-results from the Kobe expert meeting. International Journal of Environmental Research and Public Health, 16, 1309.

Généreux, M., Maltais, D., Petit, G., \& Roy, M. (2019b). Monitoring adverse psychosocial outcomes one and two years after the LacMégantic train derailment tragedy (Eastern Townships, Quebec, Canada). Prehospital \& Disaster Medicine Journal, 34, 251-259.
Goldman, E. S., \& Galea, S. (2014). Mental health consequences of disasters. Annual Review of Public Health, 35, 169-183.

Keyes, C. L. M. (2002). The mental health continuum: From languishing to flourishing in life. Journal of Health \& Social Behavior, 43, 207-222.

Keyes, C. L. M. (2005). Mental illness and/or mental health? Investigating axioms of the complete state model of health. Journal of Consulting Clinical Psychology, 73, 539-548.

Kretzmann, J., \& Mcknight, J. (1993). Building communities from the inside out: A path towards building and mobilizing a community's assets. Institute for Policy Research.

Levasseur, M., Roy, M., Michallet, B., St-Hilaire, F., Maltais, D., \& Généreux, M. (2017). Resilience, community belonging and social participation among community-dwelling older women and men: Results from the Eastern Townships Population Health Survey. Archives of Physical Medicine and Rehabilitation, 98, 2422-2432.

Lindstrom, B., \& Eriksson, M. (2010). The hitchhiker's guide to salutogenesis: Salutogenic pathways to health promotion. Tuokinprint $\mathrm{Oy}$.

Lundberg, O., \& Nyström Peck, M. (1995). A simplified way of measuring sense of coherence: Experiences from a population survey in Sweden. European Journal of Public Health, 5, 56-59.

Maltais, D., Lachance, L., Brassard, A., \& Dubois, M. (2005). Soutien social perçu, stratégies d'adaptation et état de santé psychologique post-désastre de victimes d'un désastre. Sciences sociales et santé, Paris, France, 23(2), 5-38.

Maltais, D., Lavoie-Trudeau, E., Labra, O., Généreux, M., Roy, M., Lansard, A.-L., \& Fortin, G. (2019a). Medium-term effects of a train derailment on the physical and psychological health of men. American Journal of Men's Health, July-August, 1-14.

Maltais, D., Tremblay, A.-J., Labra, O., Fortin, G., Généreux, M., Roy, M., \& Lansard, A.-L. (2019b). Seniors' who experiences the LacMégantic train derailment tragedy: What are the consequences on physical and mental health? Gerontology and Geriatric Medicine, $5,1-10$.

Maltais, D., Lansard, A. L., Roy, M., Généreux, M., Fortin, G., Cherblanc, J., Bergeron-Leclerc, C., \& Pouliot, E. (2020). Postdisaster health status of train derailment victims with post-traumatic growth. Australasian Journal of Disaster and Trauma Studies, 24, $51-63$.

McAllan, C., McAllan, V., McEntee, K., Gale, B., Taylor, D., Wood, J., et al. (2011). Lessons learned by community recovery committees of the 2009 Victorian bushfires. Advice we offer to communities impacted by disaster. $22 \mathrm{p}$.

Morgan, A., \& Ziglio, E. (2007). Revitalizing the evidence base for public health: An assets model. Promotion \& Education, 2(S2), 17-22.

O'Sullivan, T., Toal-Sullivan, D., Charles, K., Corneil, W., \& Bourgoin, M., (2013). Community Resilience Through a Functional Capabilities Lens: The CHAMPSS Framework, 18p.

O’Sullivan, T. L., Kuziemsky, C. E., Corneil, W., Lemyre, L., \& Franco, Z. (2014). The EnRiCH community resilience framework for highrisk populations. PLOS Currents Disasters, 1-19.

Roy, M., Levasseur, M., Doré, I., St-Hilaire, F., Michallet, B., Couturier, Y., et al. (2018). Looking for capacities rather than vulnerabilities: The moderating role of health assets on the association between adverse social position and health outcomes. Preventive Medicine Journal, 110, 93-99.

The Lac-Mégantic Photovoice Group, Nault-Horvath, E., Maillet, M., Stewart, C., Petit, G., \& O'Sullivan, T. (2018). Use of photovoice as a tool to support community resilience in Lac-Mégantic. In E. Ziglio (Ed.), Health 2020 priority area four: Creating supportive environments and resilient communities. A compendium of inspirational examples (pp. 163-168). World Health Organization.

United Nations. (2015). Sendai framework for disaster risk reduction 2015-2030.

Ziglio, E., Hagard, S., \& Griffiths, J. (2000). Health promotion development in Europe: Achievements and challenges. Health Promotion International, 15, 143-154. 
Open Access This chapter is licensed under the terms of the Creative Commons Attribution 4.0 International License (http://creativecommons. org/licenses/by/4.0/), which permits use, sharing, adaptation, distribution and reproduction in any medium or format, as long as you give appropriate credit to the original author(s) and the source, provide a link to the Creative Commons license and indicate if changes were made.

The images or other third party material in this chapter are included in the chapter's Creative Commons license, unless indicated otherwise in a credit line to the material. If material is not included in the chapter's Creative Commons license and your intended use is not permitted by statutory regulation or exceeds the permitted use, you will need to obtain permission directly from the copyright holder.

(c) (1) 